\title{
Breakfast, midday meals and academic achievement in rural primary schools in Uganda: implications for education and school health policy
}

\author{
Hedwig Acham'* ${ }^{*}$, Joyce K. Kikafunda ${ }^{2}$, Marian K. Malde ${ }^{3}$, \\ Wilna $\mathrm{H}$. Oldewage-Theron ${ }^{4}$ and AbdulKadir A. Egal ${ }^{4}$
}

'Department of Science, Technical and Vocational Education, Makerere University, Kampala, Uganda; ${ }^{2}$ School of Food Technology, Nutrition and Bioengineering, Makerere University, Kampala, Uganda; ${ }^{3}$ National Institute of Nutrition and Seafood Research (NIFES), Bergen, Norway; ${ }^{4}$ Centre of Sustainable Livelihoods, Vaal University of Technology,

Vanderbijlpark, South Africa

\section{Abstract}

Background: Underachievement in schools is a global problem and is especially prevalent in developing countries. Indicators of educational performance show that Uganda has done remarkably well on education access-related targets since the introduction of universal primary education in 1997. However, educational outcomes remain disappointing. The absence of school feeding schemes, one of the leading causes of scholastic underachievement, has not been given attention by the Ugandan authorities. Instead, as a national policy, parents are expected to provide meals even though many, especially in the rural areas, cannot afford to provide even the minimal daily bowl of maize porridge.

Objective: To assess and demonstrate the effect of breakfast and midday meal consumption on academic achievement of schoolchildren.

Design, Materials and Methods: We assessed household characteristics, feeding patterns and academic achievement of 645 schoolchildren (aged 9-15 years) in Kumi district, eastern Uganda, in 2006-2007, using a modified cluster sampling design which involved only grade 1 schools (34 in total) and pupils of grade four. Household questionnaires and school records were used to collect information on socio-demographic factors, feeding patterns and school attendance. Academic achievement was assessed using unstandardized techniques, specifically designed for this study.

Results: Underachievement (the proportion below a score of 120.0 points) was high (68.4\%); in addition, significantly higher achievement and better feeding patterns were observed among children from the less poor households $(p<0.05)$. Achievement was significantly associated with consumption of breakfast and a midday meal, particularly for boys $(p<0.05)$, and a greater likelihood of scoring well was observed for better nourished children (all OR values $>1.0$ ).

Conclusion: We observed that underachievement was relatively high; inadequate patterns of meal consumption, particularly for the most poor, significantly higher scores among children from 'less poor' households and a significant association between academic achievement and breakfast and midday meal consumption.

Keywords: academic achievement; primary schools; Uganda; education; school health policy

Received: 22 October 201 I; Revised: 6 December 201।; Accepted: 29 December 201 I; Published: I4 February 2012

$\mathrm{U}$ nderachievement at school or failure to reach a satisfactory level of literacy and numeracy is a global problem, particularly in developing countries (1). The numerous causes of underachievement include the poor quality of teaching, the unavailability of text books, parental resistance to formal education and low attendance rates in the classroom. Nutrition, or the lack of it, has recently been recognized as an important additional factor because studies have identified undernutrition with poor school achievement (2-4). School aged children deficient in iodine, for example, perform worse on intelligence and other tests of learning capacity 
than iodine replete children. Iron deficiency in school children also reduces some aspects of their ability to learn and providing iron improves these capacities. Hook worm infection, one cause of iron deficiency anemia and malnutrition, is also linked to diminished learning capacity. A school feeding programme in Kenya found improvements in attendance as a result of the intervention of a cup of porridge for breakfast (5). School participation was $27.4 \%$ where meals were not provided and $35.9 \%$ where they were, an improvement in attendance of about one-third (5). The higher participation was believed to have resulted both from the attraction of new children to the school and by the greater attendance of children already enrolled.

Indicators of educational performance show that Uganda has done remarkably well on education accessrelated targets since the introduction of universal primary education (UPE) in 1997 (6). There are currently over eight million children attending primary school (7), and the government requires that the parents and caretakers of these children take responsibility for feeding their children while at school. Many parents, however, particularly in the rural areas, cannot afford to pay even the minimal cost of a daily meal of maize porridge (6). Several factors including food insecurity, poverty, distance between home and school and lack of commitment make the parents involved unable to provide meals for their children (8), which is a cause of irregular school attendance, particularly in rural areas. Most pupils are unable to take a packed lunch and travel long distances to attend school; and those who stay on at school forge lunch. A participatory poverty assessment survey conducted in Uganda identified hunger and poor nutrition as key causes of absenteeism and drop-out from school (9). To alleviate this problem, interventions in the education sector, such as a national school feeding programme, is needed not only to help the disadvantaged children to access education but also to uplift educational standards, improve nutritional status, and in turn contribute to the realization of the Education for All (EFA) goals and the Millennium Development Goal 2, of ensuring that by 2015 all children, including Ugandan children, boys and girls alike, are able to complete a full course of primary schooling.

Government commitment and community participation in promoting school feeding in Uganda is evidently poor despite the large budgetary allocation $(17.5 \%$ of the total) to the sector, strong institutional capacity in government and in responsible ministries in terms of ability to perform, and strong partnerships with donor and other aid agencies (10). According to the education act (11), the responsibilities of the parents and guardians include providing food, clothing, shelter, medical care and transport. On the other hand, parents (particularly those who participated in our study) argued that, since by law all children must attend school from the age of six years, it is government's responsibility to feed these children (personal communication). The draft school health policy for Uganda (SHP) gives no clear guidelines on the place and implementation of school feeding as part of the school health programme if it were adopted (12). To date, emphasis within the SHP has centred on putting in place tools (including development of human resources) and mechanisms for supervision. There has been limited progress in implementing the proposed nutrition education or school feeding programmes within the SHP. A few interventions, usually supported by donor agencies, have recently been initiated in specific districts, particularly in the north; in the form of 'in-school feeding programs' as well as 'take-home rations' (THR). This lack of agreement between government and the parents has arisen partly because of limited documented evidence of the importance of school feeding in Uganda (13). Ekaju's study (14) citing the World Bank (15) notes that programmes that address hunger, malnutrition, and disease among schoolchildren significantly improve their academic performance, a reason why school-based feeding and health programmes can be valuable.

The aim of this study was to assess and demonstrate the effect of breakfast and midday meal consumption on academic achievement of primary schoolchildren (9-15 years) in Kumi district, eastern Uganda. Our study was guided by the research questions; what is the level of underachievement and how does it vary between boys and girls and between wealth groups; how does provision of breakfast and midday meals vary between wealth groups and how does this relate with their achievement? Uganda provides a good case for investigating issues of school quality, as current policy debates cast doubt on whether supply side factors such as teachers, classrooms, and textbooks are the most important factors for improved academic achievement given the increased education budgetary resources that have coincided with increased underachievement.

\section{Materials and methods}

\section{Study design and participants}

The study was cross-sectional, involving a random sample of 645 children in grade four (aged 9-15 years), attending 34 schools selected using a modified cluster sample design (involving only schools with more than 700 pupils as primary sampling units) in Kumi district, eastern Uganda in 2006-2007. Universal primary education, intended for all children aged 6-15 years has made many (even above 15 years) to enrol for primary school education in Uganda. Preliminary investigations in these schools indicated that only $12.2 \%$ of children in grade four were in the right grade for their age. 
No accurate estimates of children in the target grade were available at the beginning of the study in 2006 to use for sample selection. Enrolment figures for the previous academic year (2005) were used to derive the clusters and the sampling interval. The schools selected were public, mixed (co-educational) day schools. The procedure used to select the 34 schools has been described previously (16). The fourth grade was purposively selected, being a level at which transition into more complex cognitive mechanisms occur in education, that is to say, developing internally organized skills that govern behaviour in learning, remembering, and thinking (17). In the target grade we handed out numbers to all pupils present, in their order of sitting. Using a hand-held computer, we generated random numbers and the children whose numbers were selected were enrolled in the study. Out of a total sample of $1020(34 \times 30)$ children, 10 were older than 15 years, and 365 either declined participation or opted out of the study as illustrated in Fig. 1. A total of $645(63 \%)$ provided complete information on all variables (demographic, socio-economic, academic achievement and anthropometry), with results presented in this paper.

Clearance to conduct the study was obtained from the National Council for Science and Technology, after the proposal was approved by Makerere University Ethical Committee on studies dealing with human subjects. Permission was also given by the Ugandan Ministry of Education and Sports (MOES) and the District Education Office. Written informed consent was obtained from

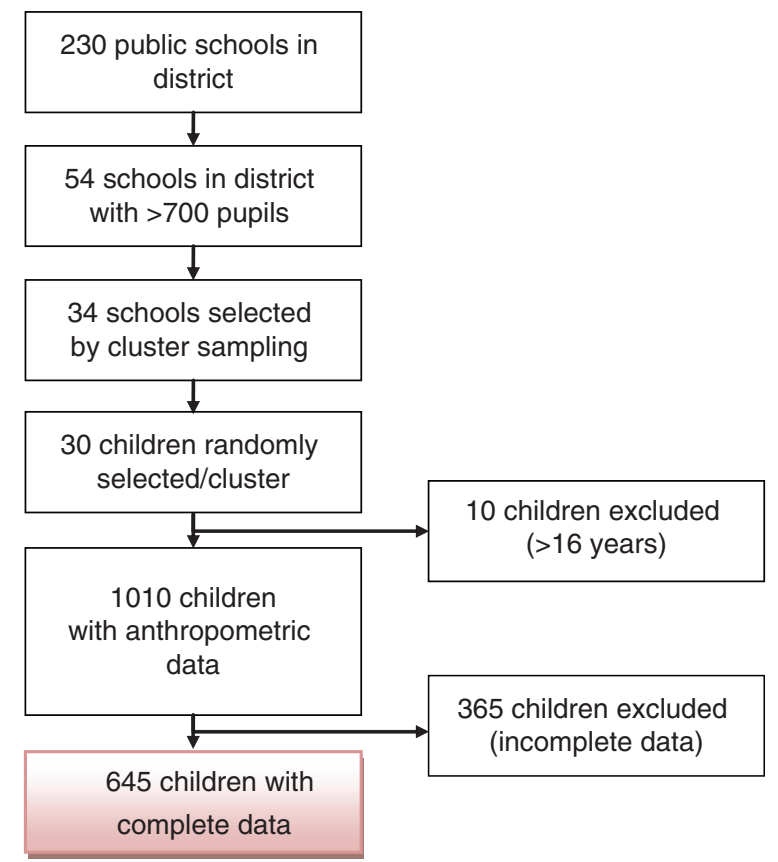

Fig. 1. Study profile showing how the 645 participating children were selected from 230 public schools. 'Complete data' means data on demographic and socio-economic variables, academic achievement and anthropometry. the parents and guardians or caretakers of all the children in the target class before their selection, following a meeting where the purpose of the study was thoroughly explained.

\section{Academic achievement}

Academic achievement was assessed using unstandardized tests in English (ELA), mathematics (MA), life skills (LSA) and oral comprehension (ORA), which were tailored to record what the children had learnt in class. Use of unstandardized methods attempted to accommodate the unique differences reported among children, a few of which include learning environments, socioeconomic backgrounds and gender (18). We also considered that this kind of testing could bring all the children to the same level of knowledge, having been taught the same content by the same teacher and under more-or-less similar learning conditions; unless otherwise stated, ELA and MA were assessed by testing the children after they had been given lessons in these subjects, following the curriculum objectives designed by the MOES. The selected children were taken out of their original classroom and taught in a separate room, which had adequate space to ensure comfort in both sitting and writing the tests, as well as teacher's movement in class to attend to the students.

The LSA test assessed common knowledge in the five domains of learning outlined by Gagné (19), which did not require any teaching at school. Questions on this subject covered a wide array of knowledge ranging from hygiene, nutrition, social and cultural attitudes, environmental issues, to HIV and AIDS awareness. The ORA test assessed comprehension, by means of an on-the-spot evaluation. The test focused on audibility, handling of text, clarity, intonation, language flow, pronunciation, punctuation, speed, confidence, addition and omission of words. The indicator of academic achievement used was the children's ability to answer correctly (relative to what they had been taught), and to read as expected. The outcomes of achievement were measured as scores of written and verbal responses, subsequently awarded out of a maximum of 100 points per subject and 400 points for all subjects (traditionally used by the Ugandan education system). The total score, rather than independent subject scores, was used in all subsequent analyses of association (as the dependent variable) due to the significant correlation between the independent subject scores $(p<0.01)$. The dependent variable was dichotomized, using a threshold value of 120.0 points $(30.0 \times 4)$, adopted on the basis of the 30.0 cut-off per subject used to define poor performance (MOES primary school pupils cumulative record card, unpublished).

Certain measures were taken to minimize the effect of factors that confound learning; these included engaging only two teachers (one for mathematics and one 
for English) to do the teaching and testing in all the 34 schools; teaching and testing the same content in all schools (similar to a national examination); teaching and testing only before lunch ( $8.00 \mathrm{am}-1.00 \mathrm{pm})$ as afternoons were reported to be poorly attended; providing a mug of porridge to all participants before lessons commenced to minimize the effect of hunger on learning, exemption of Mondays and Fridays for the teaching and testing exercises since they were reported as poorly attended days; excluding children reporting poor health from the tests and including only grade one schools. The teachers were selected based on overall performance of schools in the district for the previous year, in which case, the ones from the best school participated in the study, with approval from the district authorities. Conditionally, although their school was grade one, it could not participate in the study to minimize bias.

The two concepts taught and assessed in each subject were 'place values' and 'measures' in Mathematics; and 'tenses' and 'grammar' in English; the teaching and assessment being guided by the national curriculum. Grade one schools were initiated before implementation of UPE, and are known to have better facilities that promote learning such as teachers housing. For this reason, they attract interest and student population compared to the new schools that lack some of the facilities. It was on this basis that we selected grade one schools. We were unable to minimize the effect of background and socio-economic status, as this could only have been done by sampling siblings, which most of the participants did not have.

\section{Demographic and socio-economic attributes and school attendance}

Questionnaires were administered to households to collect demographic and socio-economic data; and school records together with classroom registers were used to collect information on school variables and attendance, respectively. Household questionnaires were administered by trained field workers. These data were collected in the homes of the children, the respondents being the parents and/or guardians of the participating children. Information on household assets and access variables was used to create an index representing the wealth of the household. Five combined assets and access variables (the presence of a working radio and a bicycle, quantity of livestock owned, nature of house, source of water, availability of electricity and type of fuel used for cooking) were used to construct the wealth index, as described by Morris et al. (20) and by Filmer and Pritchet (21). Wealth rankings were assigned to three groups ('most poor', $n=259$; 'poor', $n=257$; 'less poor', $n=129$ ). The 'not poor' were all categorized under the 'less poor'. Land ownership was not included in the construction of the wealth index, because Wamani et al.
(22) reported that possession of land in Uganda shows no differentials with stunting.

Other demographic variables (household size, mother's education level, quantity of land owned, sex of household head, child's age-group) were also dichotomized $(0,1)$. Data on school attendance (obtained from school registers) were used to calculate attendance rates. From the total number of school open-days $(n=175)$, a proportion of days attended by the child was calculated and multiplied by 100 , to obtain the attendance rate. The months of April-May and August-September had relatively fewer days due to term-breaks. These were dichotomized using a 70\% threshold to define 'poor' attendance as applied by the MOES.

\section{Food intake and feeding patterns}

Data on food intake and feeding patterns were obtained from both the household questionnaire and children's questionnaire. A section on the household questionnaire concerning child characteristics asked for information on whether the child consumed breakfast, where from and the type of meal. Similarly for midday meals, the questionnaire required information on whether the child received midday meals, where from and type of meals given. The children's questionnaire contained questions requiring similar responses as above, but directed to the child, in order to corroborate information given by the parent or guardian. The responses given for breakfast, midday meal consumption and both meals were dichotomized into 1 (participant consumed either breakfast, midday meal or both) or 0 (for none). All the above variable sets were regressed against academic achievement.

\section{Statistical analyses}

Data were entered using the Statistical Package for Social Sciences (SPSS version 15.0, 2006 SPSS Inc; Chicago, USA). Univariate analyses were conducted to obtain summary statistics (frequencies, means and standard deviations) of the variables investigated. Bivariate associations (correlation tests) were calculated to test for associations between subjects. Factor analyses were used for factor reduction, using principal component analysis to obtain the wealth Index. Multivariate analyses (GLM and Logistic regressions) were carried out to model academic achievement as a function of covariates (including household size, mother's education, land quantity owned, proportion of school days attended, gender of head of household, feeding habits, child's age category and household wealth) and for comparison of wealth groups. A $p$-value of 0.05 or less was used as the probability level at which differences were considered significant. 
Table 1. Frequency distributions of socio-demographic variables among the participants in the study $(n=645)$

\begin{tabular}{|c|c|c|}
\hline Variable & Frequency & Percentage (\%) \\
\hline \multicolumn{3}{|l|}{ Demographic variables } \\
\hline \multicolumn{3}{|l|}{ Sex } \\
\hline Girls & 348 & 54 \\
\hline Boys & 297 & 46 \\
\hline \multicolumn{3}{|l|}{ Age } \\
\hline $9-10$ years & 119 & 18.4 \\
\hline $11-12$ years & 308 & 47.8 \\
\hline $13-16$ years & 218 & 33.8 \\
\hline \multicolumn{3}{|l|}{ Type of household } \\
\hline Male headed & 526 & 81.6 \\
\hline Female headed & 119 & 18.4 \\
\hline \multicolumn{3}{|l|}{ Both parents alive \& living together } \\
\hline No & 114 & 17.7 \\
\hline Yes & 530 & 82.3 \\
\hline \multicolumn{3}{|l|}{ Mother's level of education } \\
\hline No formal education/primary incomplete & e 383 & 59.4 \\
\hline Primary complete/secondary incomplete & 211 & 32.7 \\
\hline Secondary complete and above & 51 & 7.9 \\
\hline \multicolumn{3}{|l|}{ Number of people in household } \\
\hline Five people or less & 45 & 7 \\
\hline More than 5 people & 600 & 93 \\
\hline \multicolumn{3}{|l|}{ Socio-economic variables } \\
\hline \multicolumn{3}{|l|}{ Main source of fuel for cooking } \\
\hline Firewood & 639 & 99.1 \\
\hline Others & 6 & 0.9 \\
\hline \multicolumn{3}{|l|}{ Access to electricity } \\
\hline Yes & 17 & 2.6 \\
\hline No & 628 & 97.4 \\
\hline \multicolumn{3}{|l|}{ Source of water } \\
\hline Traditional (well) only & 238 & 36.9 \\
\hline Traditional + borehole/tap & 50 & 7.8 \\
\hline Borehole/tap only & 357 & 55.3 \\
\hline \multicolumn{3}{|l|}{ Livestock ownership } \\
\hline Two animals or less & 267 & 41.4 \\
\hline More than two animals & 378 & 58.6 \\
\hline \multicolumn{3}{|l|}{ Presence of bicycle in the home } \\
\hline Yes & 507 & 78.6 \\
\hline No & 138 & 21.4 \\
\hline \multicolumn{3}{|l|}{ Access to working radio } \\
\hline Yes & 526 & 81.6 \\
\hline No & 119 & 18.4 \\
\hline \multicolumn{3}{|l|}{ Kind of house } \\
\hline Temporary house & 32 & 5 \\
\hline $\begin{array}{l}\text { Light materials (grass-thatched, mud-wall, } \\
\text { earth-floor) }\end{array}$ & I, II4 & 17.7 \\
\hline $\begin{array}{l}\text { Semi-permanent (un-baked bricks, } \\
\text { grass-thatched roof) }\end{array}$ & 374 & 58.0 \\
\hline $\begin{array}{l}\text { Single rented apartment in trading centre/ } \\
\text { town }\end{array}$ & e/ 15 & 2.3 \\
\hline
\end{tabular}

Table 1 (Continued)

\begin{tabular}{|c|c|c|}
\hline Variable & Frequency & Percentage (\%) \\
\hline Solid materials/permanent & 110 & 17.1 \\
\hline \multicolumn{3}{|l|}{ (baked-bricks, iron-roof \& cement-floor) } \\
\hline \multicolumn{3}{|l|}{ Land ownership } \\
\hline $0-$ I.l ha & 228 & 35.3 \\
\hline I.2-4.0 ha & 367 & 56.9 \\
\hline More than 4.0 ha & 50 & 7.8 \\
\hline \multicolumn{3}{|l|}{ Wealth groups } \\
\hline First tercile (lowest wealth category) & 259 & 40.2 \\
\hline Second tercile (middle wealth category) & 367 & 39.8 \\
\hline Third tercile (highest wealth category) & 50 & 20.0 \\
\hline \multicolumn{3}{|l|}{ Nutritional status } \\
\hline \multicolumn{3}{|l|}{ BMI-for-age } \\
\hline Normal & 580 & 89.9 \\
\hline Thin/wasted & 65 & 10.1 \\
\hline \multicolumn{3}{|l|}{ Height-for-age } \\
\hline Normal & 589 & 91.3 \\
\hline Stunted & 56 & 8.7 \\
\hline \multicolumn{3}{|l|}{ Weight-for-age } \\
\hline Normal & 561 & 87.0 \\
\hline Underweight & 84 & 13.0 \\
\hline \multicolumn{3}{|l|}{ School factors } \\
\hline \multicolumn{3}{|l|}{ Attendance } \\
\hline Less than $70 \%$ & 113 & 24.5 \\
\hline More than $70 \%$ & 348 & 75.5 \\
\hline \multicolumn{3}{|l|}{ Breakfast } \\
\hline No & 478 & 74.1 \\
\hline Yes & 167 & 25.9 \\
\hline \multicolumn{3}{|l|}{ Midday meal } \\
\hline No & 286 & 44.3 \\
\hline Yes & 359 & 55.7 \\
\hline \multicolumn{3}{|l|}{ Feeding } \\
\hline Has no meal at all & 251 & 38.9 \\
\hline Has breakfast, lunch or both & 394 & 61.1 \\
\hline
\end{tabular}

\section{Results}

\section{Characteristics of the participants}

Most of the participants were aged 11 to 12 years (Table 1), of whom most were from male-headed households and lived with both parents. More than half were born to mothers who had either no formal education or had incomplete primary education, and lived in relatively large households (with more than 5 people). The main source of fuel for most households was wood; few $(2.6 \%)$ had access to electricity for lighting. More than half of the households had access to safe drinking water, owned livestock and at least a bicycle in the home, as a means of transportation (63.3, 58.6 and $78.6 \%$, respectively). Access to a working radio was also high $(81.6 \%)$, but the general quality of 
housing was 'poor' with the majority of the respondents $(58.0 \%)$ living in semi-permanent, unbaked brick houses, with an earth floor and grass-thatched roof. Land ownership was high, with the majority of the households (56.9\%) owning between 1.2-4.0 hectares of land. Putting these characteristics together, however, placed more of the participants $(40.2 \%)$ in the lowest wealth category compared to those in the middle $(39.8 \%)$ and highest wealth categories $(20.0 \%)$. The nutritional status of these children has already been reported (16), with $10.1,8.7$, and $13.0 \%$ rates of thinness (low BMI-for-age), stunting (low heightfor-age), and underweight (low weight-for-age), respectively. These values were significantly higher for boys than girls $(p<0.001)$. Accordingly, 89.9, 91.3 and 87.0\% were of normal BMI-for-age, height-for-age and weight-for-age; respectively. Overweight was negligible, with only one child $(0.2 \%)$ having weight-for-age higher than normal (WAZ > 2.0). However, 17 (2.6\%) had height-for-age higher than normal (HAZ > 2.0). Only data for normal children was used in subsequent analyses with academic achievement.

\section{Academic achievement and predictors}

The average score for the group was $100.0 \pm 47.1$ [95\% CI 96.3-103.6]; $99.0 \pm 45.6$ [95\%CI 94.2-103.8] for girls and $101.1 \pm 48.9$ [95\% CI 95.5-106.6] for boys (Table 2); with a non-significant mean difference of -2.1 points $(p=0.58)$. Achievement between girls and boys in respective subjects was not statistically significant except in mathematics (MA) where, despite the poor achievement (less than 30.0 points), boys had a significantly higher score than the girls $(p<0.001)$. More than half the children (68.4\%) scored below the 120.0-points threshold.

Scores in relation to wealth indicated that the 'most poor' group had a mean of $96.8 \pm 44.4$; the 'poor' had $91.5 \pm 42.4$, whereas the 'less poor' had a higher mean of $123.1 \pm 53.7$ points.

Table 3 shows how provision of meals and scores of achievement varied between wealth groups. Multiple comparisons between the three wealth groups, assuming equal sample sizes and variances (Tukey procedure); unequal sample sizes (Bonferroni procedure) or equal variances not assumed at all (Tamhane procedures), indicated that group means for both feeding patterns and academic achievement of the 'most poor' differed significantly from those of the 'less poor' (all $p$ values $<0.001$ ). These tests revealed that the pattern of consumption of meals and scores of achievement between these two groups differed. However, the difference in patterns of meal consumption between the 'most poor' and the 'poor' did not significantly differ (assuming or not assuming equal variances and sample sizes). Accordingly, the group means for academic achievement for the 'most poor' significantly differed from those of the 'less poor'. Equally, those of the 'poor' differed significantly from those of the 'less poor' (for all multiple comparisons procedures, p values $<0.05$ ). However, the group means of the 'most poor' and the 'poor' did not significantly differ (all p values $>0.05$ ) (Table 3 ). Taken together, these results suggest that wealth status did have an effect on feeding patterns of the children, and in-turn their academic achievement. Specifically, our results suggest that children from the lowest quintile of wealth (most poor) were not adequately feeding compared to those from the highest quintile. Accordingly, these children had lower scores than their counterparts. However, it should be noted that differences between wealth status must be large enough in order to see an effect, in which case the 'poor' did not appear to significantly show differences in both feeding patterns and academic achievement with the 'most poor'.

Logistic regression models including breakfast alone, midday meal alone and then combined (Table 4) indicated that compared to independent meals, a child who was reported to consume both breakfast and midday meals was more likely to score higher than those who had only one type of meal. However, of the two types again, midday meals had a (non-significant) stronger effect on achievement compared to breakfast $(\mathrm{OR}=1.25,95 \%$ CI $0.8-1.8$; 1.20 , 95\% CI 0.8-1.8; respectively) (Table 4). This effect was however marginally significant among boys $(p<0.1)$.

Logistic regression analyses between achievement and the variables that were dichotomized are presented in

Table 2. Achievement test scores for the combined group $(n=645)$

\begin{tabular}{|c|c|c|c|c|c|}
\hline Subjects & $\begin{array}{l}\text { Combined }(n=645) \\
\text { Mean } \pm D(95 \% \mathrm{Cl})\end{array}$ & $\begin{array}{c}\text { Girls }(n=348) \\
\text { Mean } \pm \text { SD }(95 \% \mathrm{Cl})\end{array}$ & $\begin{array}{c}\text { Boys }(n=297) \\
\text { Mean } \pm \text { SD }(95 \% \mathrm{Cl})\end{array}$ & Mean difference & $\begin{array}{l}P \text { value for the } \\
\text { difference }\end{array}$ \\
\hline ELA & $21.9 \pm 16.3(20.6,23.1)$ & $22.5 \pm 16.1(20.8,24.2)$ & $21.1 \pm 16.5(19.2,23.0)$ & 1.4 & 0.27 \\
\hline MA & $12.5 \pm 7.8(11.9,13.1)$ & $11.4 \pm 7.3(10.6,12.1)$ & $13.9 \pm 8.2(13.0,14.8)$ & -2.5 & $<0.001$ \\
\hline LSA & $27.9 \pm 14.4(26.8,29.0)$ & $27.0 \pm 14.4(25.5,28.5)$ & $29.0 \pm 14.3(27.3,30.6)$ & -1.9 & 0.09 \\
\hline ORA & $37.7 \pm 21.0(36.0,39.3)$ & $38.1 \pm 20.7(35.9,40.3)$ & $37.1 \pm 21.4(34.7,39.6)$ & 1.0 & 0.56 \\
\hline Grand mean & $254.0 \pm I I .8(24.1,25.9)$ & $24.8 \pm I I .4(23.6,26.0)$ & $25.3 \pm 12.2(23.9,26.7)$ & -0.5 & 0.58 \\
\hline Grand total score & $100.0 \pm 47.1(96.3,103.6)$ & $99.0 \pm 45.6(94.2,103.8)$ & $101.1 \pm 48.8(95.5,106.6)$ & -2.1 & 0.58 \\
\hline
\end{tabular}

Note: Scores are presented as means \pm SD, with $95 \%$ confidence intervals in parentheses. 
Table 3. Multiple comparisons of breakfast and lunch intake and academic achievement levels between wealth groups $(n=645)$

\begin{tabular}{|c|c|c|c|c|c|c|c|}
\hline \multirow[b]{2}{*}{ Dependent Variable } & \multirow[b]{2}{*}{ procedure } & \multirow[b]{2}{*}{ (I) groups of wealth } & \multirow[b]{2}{*}{ (J) groups of wealth } & \multirow[b]{2}{*}{ Mean Difference $(I-J)$} & \multirow[b]{2}{*}{$P$} & \multicolumn{2}{|c|}{ 95\% Confidence interval } \\
\hline & & & & & & Upper bound & Lower bound \\
\hline \multirow[t]{18}{*}{ Meals at school $(0,1)$} & Tukey HSD & Most poor & Poor & 0.1 & .082 & 0.0 & 0.2 \\
\hline & & & Less poor & $-0.3(*)$ & .000 & -0.3 & -0.1 \\
\hline & & Poor & Most poor & -0.1 & .082 & -0.2 & 0.0 \\
\hline & & & Less poor & $-0.4(*)$ & .000 & -0.5 & -0.2 \\
\hline & & Less poor & Most poor & $0.4(*)$ & .000 & 0.1 & 0.4 \\
\hline & & & Poor & $0.4(*)$ & .000 & 0.2 & 0.5 \\
\hline & Bonferroni & Most poor & Poor & 0.1 & .098 & 0.0 & 0.2 \\
\hline & & & Less poor & $-0.3(*)$ & .000 & -0.4 & -0.1 \\
\hline & & Poor & Most poor & -0.1 & .098 & -0.2 & 0.0 \\
\hline & & & Less poor & $-0.4(*)$ & .000 & -0.5 & -0.2 \\
\hline & & Less poor & Most poor & $0.3(*)$ & .000 & 0.1 & 0.4 \\
\hline & & & Poor & $0.4(*)$ & .000 & 0.2 & 0.5 \\
\hline & Tamhane & Most poor & poor & 0.1 & .123 & 0.0 & 0.2 \\
\hline & & & Less poor & $-0.3(*)$ & .000 & -0.4 & -0.2 \\
\hline & & Poor & Most poor & -0.1 & .123 & -0.2 & 0.0 \\
\hline & & & Less poor & $-0.4(*)$ & .000 & -0.5 & -0.2 \\
\hline & & Less poor & Most poor & $0.3(*)$ & .000 & 0.2 & 0.4 \\
\hline & & & poor & $0.4\left(^{*}\right)$ & .000 & 0.2 & 0.5 \\
\hline \multirow[t]{18}{*}{ Total score } & Tukey HSD & Most poor & poor & 5.4 & .377 & -4.1 & 14.8 \\
\hline & & & Less poor & $-26.3(*)$ & .000 & -37.8 & -14.8 \\
\hline & & Poor & Most poor & -5.4 & .377 & -14.8 & 4.1 \\
\hline & & & Less poor & $-31.7\left(^{*}\right)$ & .000 & -43.2 & -20.1 \\
\hline & & Less poor & Most poor & $26.3(*)$ & .000 & 14.8 & 37.8 \\
\hline & & & poor & $31.7(*)$ & .000 & 20.1 & 43.2 \\
\hline & Bonferroni & Most poor & Poor & 5.4 & .549 & -4.3 & 15.0 \\
\hline & & & Less poor & $-26.3(*)$ & .000 & -38.1 & -14.5 \\
\hline & & Poor & Most poor & -5.4 & .549 & -15.0 & 4.3 \\
\hline & & & Less poor & $-31.7\left(^{*}\right)$ & .000 & -43.5 & -19.8 \\
\hline & & Less poor & Most poor & $26.3(*)$ & .000 & 14.5 & 38.1 \\
\hline & & & poor & $31.7\left(^{*}\right)$ & .000 & 19.8 & 43.5 \\
\hline & Tamhane & Most poor & Poor & 5.4 & .411 & -3.8 & 14.5 \\
\hline & & & Less poor & $-26.3(*)$ & .000 & -39.5 & -13.1 \\
\hline & & Poor & Most poor & -5.4 & .411 & -14.5 & 3.8 \\
\hline & & & Less poor & $-31.7(*)$ & .000 & -44.7 & -18.6 \\
\hline & & Less poor & Most poor & $26.3(*)$ & .000 & 13.1 & 39.5 \\
\hline & & & poor & $31.7(*)$ & .000 & 18.6 & 44.7 \\
\hline
\end{tabular}

Notes: 0, None; I, Yes (breakfast, lunch or both are provided to the child).

*Differences are significant at $p<0.05$.

Tables 4 and 5. As a group, achievement was positively associated, albeit not significantly, with age category of the children, mother's education level, attendance rates and feeding patterns (Table 4). Children were more likely to score above the threshold if they were less than 11 years of age $(\mathrm{OR}=1.1 ;[95 \%$ CI $0.7-1.7])$. Those born to mothers who had completed primary education and above had higher chances of scoring points above the threshold (OR $=1.4 ;$ [95\% CI 1.0-2.1]). Children whose attendance rates were above $70 \%$ were more likely to score highly (OR $=1.5$; [95\% CI 1.0-2.3]) and, similarly, those reported to consume breakfast, midday meals or both had increased chances of scoring above the threshold $(\mathrm{OR}=1.3$; [95\% CI $0.9-2.0])$. All factors that were significant in the model (household size, quantity of land owned and household head) negatively predicted achievement, meaning that if a child came from a relatively small household, he or she was significantly less likely to score the threshold $(\mathrm{OR}=0.4 ;[95 \%$ CI $0.2-0.9])$. Similarly, children who came from households who owned 
Table 4. Logistic regression model between academic achievement and its covariates

\begin{tabular}{|c|c|c|c|}
\hline \multirow[b]{2}{*}{ Variables } & \multicolumn{3}{|c|}{$\operatorname{EXP}(\mathrm{B}), 95 \% \mathrm{Cl}$} \\
\hline & Combined $(n=645)$ & Girls $(n=348)$ & Boys $(n=297)$ \\
\hline Feeding $(\mathrm{I}=$ Breakfast $)$ & $1.20(0.8-1.8)$ & I.16 (0.7-2.0) & $1.52(0.7-3.1)$ \\
\hline Household size ( $I=<5$ people) & $0.40(0.2-0.9)^{*}$ & $0.5 \mid(0.2-1.5)$ & $0.3 \mid(0.1-1.3)$ \\
\hline Age category $(\mathrm{I}=<\mathrm{II}$ years $)$ & $1.05(0.6-1.7)$ & $0.95(0.5-1.8)$ & $1.28(0.6-2.8)$ \\
\hline Mother's education ( $\mathrm{I}=$ primary complete and above) & $1.4 \mid(1.0-2.1)$ & $1.41(0.8-2.4)$ & $1.33(0.7-2.5)$ \\
\hline Land $(I=I .2 I$ or more ha $)$ & $0.59(0.4-0.8)^{* *}$ & $0.96(0.6-1.6)$ & $0.32(0.2-0.6)^{* * * *}$ \\
\hline Attendance level ( $70 \%$ rate or more) & $1.52(1.0-2.3)^{*}$ & I.I $5(0.7-2.0)$ & $2.25(1.2-4.2)^{*}$ \\
\hline Household head ( $I=$ male headed $)$ & $0.44(0.3-0.7)^{* * * *}$ & $0.40(0.2-0.7)^{* *}$ & $0.480 .2-0.9)^{*}$ \\
\hline Feeding ( $\mathrm{I}=$ midday meals $)$ & $1.25(0.8-1.8)$ & $1.06(0.6-1.8)$ & $1.79(0.9-3.4)^{\dagger}$ \\
\hline Household size ( $I=<5$ people) & $0.39(0.2-0.9)^{*}$ & $0.52(0.2-1.5)$ & $0.28(0.1-1.2)^{\dagger}$ \\
\hline Age category $(\mathrm{I}=<\mathrm{II}$ years $)$ & $1.05(0.6-1.7)$ & $0.96(0.5-1.8)$ & $1.29(0.6-2.9)$ \\
\hline Mother's education ( $\mathrm{I}=$ primary complete and above) & $1.40(0.9-2.1)$ & $1.41(0.8-2.4)$ & $1.36(0.7-2.5)$ \\
\hline Land $(I=I .2 \mid$ or more ha $)$ & $0.58(0.40 .8)^{* *}$ & $0.95(0.6-1.6)$ & $0.31(0.2-0.6)^{* * * *}$ \\
\hline Attendance level ( $70 \%$ rate or more) & $1.46(1.0-2.2)^{\dagger}$ & $1.15(0.6-2.1)$ & $2.05(1.1-3.9)^{*}$ \\
\hline Household head ( $I=$ male headed $)$ & $0.42(0.3-0.6)^{* * *}$ & $0.40(0.2-0.7)^{* *}$ & $0.40(0.2-0.8)^{*}$ \\
\hline Feeding ( $\mathrm{I}=$ both breakfast and midday meals) & $1.28(0.9-2.0)$ & $1.07(0.7-1.9)$ & $1.99(1.0-3.9)^{*}$ \\
\hline Household size ( $I=<5$ people) & $0.38(0.2-0.9)^{*}$ & $0.52(0.2-1.6)$ & $0.26(0.1-1 . I)^{\dagger}$ \\
\hline Age category $(\mathrm{I}=<\mathrm{II}$ years $)$ & $\mathrm{I} .05(0.7-\mathrm{I} .7)$ & $0.96(0.5-1.8)$ & $1.30(0.6-2.9)$ \\
\hline Mother's education $(\mathrm{I}=$ primary complete and above $)$ & $1.39(1.0-2.1)$ & $1.4 \mid(0.9-2.5)$ & $1.26(0.7-2.4)$ \\
\hline Land $(I=I .2 I$ or more ha $)$ & $0.58(0.40 .9)^{* *}$ & $0.95(0.6-1.6)$ & $0.29(0.2-0.5)^{* * * *}$ \\
\hline Attendance level ( $70 \%$ rate or more) & $1.44(1.0-2.3)^{\dagger}$ & $1.15(0.6-2.1)$ & $2.00(1.1-3.9)^{*}$ \\
\hline Household head ( $I=$ male headed $)$ & $0.42(0.3-0.7)^{* * *}$ & $0.40(0.2-0.8)^{* *}$ & $0.4 \mathrm{I}(0.2-0.8)^{*}$ \\
\hline
\end{tabular}

Notes: Values presented are parameter estimates, with $95 \%$ confidence intervals. Dependent variable; $I=\geq \mid 20.0$ points, $0=<\mid 20.0$ points.

*Significant at $p<0.05$.

**Significant at $p<0.01$.

*** Significant at $p<0.001$.

'Significant at $p<0.1$.

Table 5. A logistic regression between covariates and achievement among boys, based on different levels of nutritional status $(n=297)$.

\begin{tabular}{|c|c|c|c|c|c|c|}
\hline \multirow[b]{3}{*}{ Variables } & \multicolumn{6}{|c|}{$\operatorname{EXP}(\mathrm{B})$} \\
\hline & \multicolumn{2}{|c|}{ BMI-for-age } & \multicolumn{2}{|c|}{ Height-for-age } & \multicolumn{2}{|c|}{ Weight-for-age } \\
\hline & a & b & $\mathrm{a}$ & b & a & b \\
\hline Feeding ( $\mathrm{I}=$ both breakfast and midday meals $)$ & 2.1 & $2.1^{*}$ & 0.6 & $2.0 *$ & 1.8 & $1.9^{\dagger}$ \\
\hline Household size ( $I=<5$ people $)$ & 7.3E9 & $0.2^{*}$ & I.2E9 & $0.2 *$ & 3.IE9 & $0.2^{\dagger}$ \\
\hline Age category $(I=<I I$ years $)$ & - & 1.3 & I.7EIO & 1.1 & $5.4 \mathrm{E} 10$ & 1.1 \\
\hline Mother's education ( $I$ = primary complete and above) & 1.5 & 1.4 & 0.2 & 1.5 & 0.6 & 1.5 \\
\hline Land $(I=I .2 I$ or more ha $)$ & 0.3 & $0.3 * * *$ & 2.1 & $0.3^{* * * *}$ & 0.4 & $0.3^{* * *}$ \\
\hline Attendance level ( $70 \%$ or more) & 1.1 & $2.3^{*}$ & 10.0 & $2.0^{*}$ & 2.9 & $2.0^{*}$ \\
\hline Household head ( $\mathrm{I}=$ male headed $)$ & 1.8 & $0.3 * *$ & 0.2 & $0.4^{*}$ & 0.4 & $0.4^{*}$ \\
\hline
\end{tabular}

Notes: a, undernourished; b, normal. Dependent variable; $I=\geq 120.0$ points, $0=<120.0$ points.

*Significant at $p<0.05$.

**Significant at $p<0.01$.

*** Significant at $p<0.001$.

'Significant at $p<0.1$.

$\mathrm{E} 9=\left(\times 10^{\wedge} 9\right)$

$\mathrm{EIO}=\left(\times 10^{\wedge} 10\right)$ 
relatively large quantities of land (more than $1.2 \mathrm{ha}$ ) were significantly less likely to score the threshold $(\mathrm{OR}=0.6$; [95\% CI 0.4-0.9]), and those from households headed by males were significantly less likely to score the threshold of 120.0 points $(\mathrm{OR}=0.4$; [95\% CI $0.3-0.6])$.

When treated according to gender, household size, age category and mother's education consistently showed similar trends with both boys and girls, with no significant difference (all p values $>0.05$ ). The sex of the household head was consistently negatively associated with achievement in both boys and girls, whereas quantity of land owned was significant for boys but not for girls. Attendance rates and feeding patterns, which were not significant for the whole group, turned out to be significant predictors, the effect being evident among boys but not among girls.

The relationship between anthropometric indicators (height, weight and body mass index) and academic achievement of these children has been reported in Acham et al. (23). A logistic regression model in which undernourished children were compared with their healthy counterparts, for all dichotomized variables, is presented in Table 5. We observed clear patterns among children who were normal (in terms of BMI-for-age, height-for-age and weight-for-age), with results indicating that the age category of the child, mother's education, attendance rates and feeding patterns positively predicted achievement, whereas land ownership was less important. Of the four variables, attendance rates and feeding patterns were significant ( $\mathrm{p}$ values $<0.05$ ).

\section{Discussion}

Our findings indicated unsatisfactory academic achievement in terms of test scores, which did not significantly differ between boys and girls; a pattern of inadequate consumption of meals by the schoolchildren, particularly those from the 'most poor' households. We also recorded significantly higher scores among children from 'less poor' households who in turn demonstrated more satisfactory patterns of meal consumption; and a significant association between academic achievement and the consumption of breakfast and midday meals.

Underachievement of children at elementary school has been widely recognized in Uganda in general $(24,25)$ and in the Teso region in particular, where this study was conducted (26). Many reasons have been given for this including poor teaching, teachers' lack of commitment to their work, large classes, poor school facilities, minimal homework given to pupils, lack of a reading culture among both teachers and pupils, and an absence of efficient leadership in schools (26).

Elsewhere, a critical link has been shown between learning and schoolchildren's health and nutrition, where poor health and under-nutrition have been found to adversely affect scholastic achievement (27). In Uganda, however, studies of feeding and achievement are scarce, but one controlled field experiment (14) indicated that 'in-school feeding programmes' (SFP) and take-home rations (THR) conditional on school attendance had significant effects on mathematics test scores of children 11-14 years in the camps of internally displaced people. Notwithstanding the impact of such food for education programmes, in Uganda they are externally driven by donors-with limited uptake in other parts of the country not affected by civil war.

Giving children a daily breakfast or a meal at school improves their scholastic achievement through several mechanisms, for example by activation of the brain, which is sensitive to short-term variations in the availability of nutrient supplies $(3,28)$. This indication is particularly strong for undernourished children. Meals at school also play important roles in alleviating short-term hunger in malnourished or even well-nourished children, motivate parents (especially among the poor) to enroll their children in school and have them attend regularly, address micronutrient deficiencies among children and increase community participation and involvement in schools (27). Our finding on the relationship between provision of breakfast and midday meals with academic achievement should be given credibility as it has provided a picture of the experience of rural schoolchildren in Uganda. Regular attendance is closely related to scholastic achievement, which our study also demonstrated. We found that an attendance rate above $70 \%$ was significantly positively associated with achievement, corroborating findings by others (29).

During the study, we observed that children who did not go home for lunch, possibly due to distance, stayed in school until the end of the school day, which means that they continued attending school while hungry. We also observed that often some of the children who went home for lunch did not report back for afternoon lessons. Moreover, $90 \%$ of the schools in our study did not have operational canteens or tuck shops where children could buy snacks in case of need. Half of the schools had no access to safe drinking water; defined in the Uganda Demographic Health Survey report (30) as borehole, piped or tap water. Absence of these facilities in schools would be less of a concern if children were provided with at least a meal or a snack at school. Our results, when treated by the type of meal indicated that midday meals had stronger effects on achievement compared to breakfast (Table 4). However, the effect was much stronger when both meals were provided.

Supplementary feeding provided to schoolchildren in Uganda is currently limited to formerly conflict-affected areas and pastoralist communities. Of all children attending primary school (over eight million), a total of only 48,000 are fed by government through its partners, most notably the World Food Programme (8). With the 
closing of Internally Displaced People's (IDP) camps in northern Uganda, there are prospects that education could inevitably suffer. With the return to their ancestral homes after over two decades, school attendance may be affected in the short term, as hunger will affect school attendance and learning outcomes.

Hunger in school is likely to be a significant problem in various other rural areas with similar conditions to the one currently investigated. The long distances that children walk, cultural meal practices that include no breakfast and midday meals but only supper as demonstrated by our findings, and a lack of family time or resources to provide adequate meals to children before and during the school day, subject these children to such conditions of hunger. A parallel study on the quality of dietary intake among these children (31) indicated that where children had breakfast, it consisted mainly of plain tea or tea with milk and ground nuts, or millet porridge, leftovers of rice or maize meal. A typical lunch for those eating at home included cassava bread with sorghum or maize meal for some; the common accompaniment was legumes, onions, cabbages and tomatoes. Supper, which was always the main meal of the day, comprised the same foods that were prepared for lunch. The Teso region, where our study was conducted, is known as a highly food-insecure region (32). A recent assessment indicated borderline access to adequate food with recurrent high vulnerability due to erratic rains and drought. Simply alleviating this hunger in schoolchildren through school feeding may help buffer the effects of the recurrent famine, and assist the children in taking full advantage of the education offered to them. Our strategy of providing a mug of maize porridge before lessons began seemingly benefited the children emotionally, as observed by their participation in the classroom, which supports the reports of Pollit et al. (33).

Countries where school feeding has been successfully implemented including South Africa, Ghana, Kenya and Angola (34), have registered improved primary school enrolments, $90-95 \%$ retention rates-in comparison to Uganda, whose current retention rate is $52 \%$ (8).

Uganda has done well in terms of enrolments; the government invests the highest allocation of its public spending $(17.5 \%)$ on education. With the current enrolment at 8.2 million children, the literacy gap between boys and girls has been narrowed, which may explain our finding of a non-significant difference in achievement between boys and girls; despite literature reports that often indicate that boys perform better than the girls (35). Our study revealed a significant difference in mathematics test results only, when the results were treated by independent subject scores. We believe that the gap between boys and girls in this population could be further reduced if there were uniform school feeding programmes.
As Uganda progresses towards the goal of education for all, this initial success of high enrolment places greater emphasis on increasing the quality of learning within the classroom and school. Without diminishing the importance of the current school inputs, teacher quality and classroom organization, it is apparent that optimizing school performance also requires additional investments in the health and nutrition of the children at school. Our findings of poor performance among the most poor households, which in-turn had poor patterns of feeding suggest a need for government to re-think the issue of school feeding especially for the rural poor. Providing a daily meal to a child from a food-insecure household also enhances equity of access to education. School feeding programmes are highly visible and, as a result, often have a significant political dimension, particularly because they can represent a considerable income transfer not only by contributing to the overall family budget, but also offset in part the opportunity costs of sending children to school (36). For this reason, they should be supported so as to promote development.

We found factors other than meals that influence scholastic achievement, including household size, age of the child, mother's education level, land owned by the household and the sex of the household head. Children from larger households, defined as a household with more than five people (30), were significantly more likely to score more highly than their counterparts from smaller households, in contrast to the findings of other authors (37). Our finding might be supported by the fact that the number of family members in the household benefits children, by the fact that siblings' or older members' encouragement in terms of rewards for good performance, or even provision of direct support with homework and or serving as role models encourages good performance. Children aged less than 11 years were found to perform better, possibly because at this age children are still able to take more advantage of schooling than the older pupils. Moreover, the status of older children is precarious as they, rather than the younger ones, would likely be withdrawn if there were economic or social pressures at home due to their greater ability to contribute to household economic production. Similarly, the dummies for male-headed households and land area owned by the household negatively influenced achievement, significantly among boys. This finding agrees with others (38) and is possibly because the boys experience pressures to assist their fathers in domestic work. The negative association between the ownership of land and achievement at school may be due to greater demand for child labour. Land ownership in Uganda has also been found to have a negative influence on nutritional status of children under five (22).

Evidence of the importance of parental education in shaping children's school performance is mixed. In Egypt, 
student performance was marginally, but positively, influenced by the father's educational level but that mother's education did not play a significant role (39). However, in Ethiopia (40), it was found that family educational background was not important in explaining differences in achievement, particularly in mathematical computing skills. In the case of Peru, education levels of female adults in the family (not just the caregivers) were found to be positively associated with children's educational outcomes (41). These support our findings, suggesting the need to invest in girls' education.

\section{Limitations}

Our findings may be limited by the fact that the study was not interventional, but was based on reported data, with unknown quality and quantity of foods consumed daily by the children. Secondly, not having been interventional, cases of misreporting were likely. It is possible that children who go home for lunch are not provided with food and because of time constraints they return to school unfed for the afternoon classes. For the future, we recommend that data collected on food intake record their actual food intake. Lastly, it is hard to infer a causeand-effect relationship between feeding and achievement, because there are several confounding factors that are likely to influence achievement. In spite of the relative crudeness of the achievement tests used we believe our findings should be given credibility because we were able to capture a relatively holistic picture of the situation in the rural schoolchildren in Uganda.

\section{Conclusion and recommendations}

We found relatively high scholastic underachievement among the children; no significant difference in achievement between boys and girls; that meal consumption was most inadequate among children from the 'most poor' households; that children from 'less poor' households scored significantly higher than others; and a significant association between meal consumption and academic achievement. The definite link observed between regular meals and children's academic achievement suggests a need for policy-makers to re-consider the issue of school feeding, especially in the rural areas and among the 'most poor' households, where performance at school proved to be important.

\section{Acknowledgements}

We gratefully acknowledge financial support from Carnegie cooperation (New York), the Norwegian Programme for Development, Research and Education (NUFU) and Makerere University graduate school. At the time of the study, Hedwig Acham was a graduate student at Makerere University. The data presented in this paper come from Acham's PhD thesis and she acknowledges her thesis committee. We also thank the teachers, parents and children who participated in the study; and the South Africa Netherlands
Research Programme on Alternatives to Development (SANPAD) for facilitating the writing and review of the manuscript. Albert Modi provided helpful advice on the article.

\section{Conflict of interest and funding}

This research work was funded by Carnegie cooperation of New York and the Norwegian Programme for Development, Research and Education (NUFU). The writing and review of the article was facilitated by SANPAD. There are no conflicts of interest to be reported.

\section{References}

1. Simeon DT. School feeding in Jamaica: a review of its evaluation. Am J Clin Nutr 1998; 67: 790S-4S.

2. Powell CA, Grantham-McGregor SM. The association between nutritional status, school achievement and school attendance in twelve-year-old children at a Jamaican school. W Indian Med J 1980; 29: 247-53.

3. Grantham-McGregor SM, Chang S, Walker SP. Evaluation of school feeding programmes: some Jamaican examples. Am J Clin Nutr 1998; 67: 785S-9S.

4. Ahmed AU. Impact of feeding children in school: evidence from Bangladesh. Washington, DC: International Food Policy Research Institute; 2004.

5. Vermeersch C, Kremer M. (2004). School meals, educational achievement, and school competition: evidence from a randomized evaluation. World Bank Policy Research working paper No. 3523. Washington, DC: World Bank.

6. Global Child Nutrition Forum (GCNF). School Feeding in Uganda, 2006. Report for the Global Child Nutrition Forum. http://www.gcnf.org/library/country-reports/uganda/2006Uganda-School-Feeding.pdf [cited 25 August 2011].

7. Education Management Information System. EMIS Abstract 2009. Ministry of Education and Sports, Republic of Uganda. http://www.education.go.ug/emis-statistics/statisticsabstarct.html [cited 8 October 2011]

8. WFP, Technical reports. Evaluation of WFP's development and recovery portfolio in Uganda, September, 2004. In: Learning from experience good practices from 45 years of school feeding. http://documents.wfp.org/stellent/groups/public/documents/ reports/wfp065910.pdf [cited 10 August 2011].

9. Civil society Organization issues paper on Social protection. Social protection for Uganda's most vulnerable and chronically poor: Issues, challenges and options. 2008. http://www.ebpdn. org/download/download.php?table=resources\&id $=2343 \quad$ [cited 25 August 2011].

10. Devereux S, Sabates-Wheeler R. (2004). Transformative social protection. IDS working paper, No. 232. Institute of Development studies. XPS Publishers, Brighton, UK.

11. Education Act: pre-primary, primary and post-primary education-Act, 2008, (act 13 supplement). (2008). Kampala: UPPC [Internet]. http://www.education.go.ug/EducationAct.pdf [cited October 2011].

12. Masembe-Kasirye FN. Efforts to introduce milk in school feeding programmes in Uganda. First eastern and southern Africa school milk programme conference 2005. http:// www.fao.org/es/ESC/common/ecg/187/en/Uganda.pdf [cited 8 October 2011].

13. Adelman S, lderman H, Gilligan DO, Lehrer K. The Impact of alternative food for education programmes on learning achievement and cognitive development in Northern Uganda. Washington, DC: International Food Policy Research Institute; 2008. 
14. Ekaju, J. An investigation into the relationship between the 1997 Universal Primary Education (UPE) Policy and regional poverty and educational inequalities in Uganda (1997-2007). Thesis, University of Glasgow, 2011.

15. World Bank. Learning for all: investing in people's knowledge and skills to promote development: World Bank Group Education Strategy 2020 Executive Summary, April 2011. http:// siteresources.worldbank.org/EDUCATION/Resources/ESSU/ Education_Strategy_2020_Executive_Summary_4_12_2011.pdf [cited 8 October 2011].

16. Acham H, Kikafunda JK, Tylleskar T, Malde MK. Nutritional and health status of primary schoolchildren in rural uganda. Afr J Food Agr Nutr Dev 2011; (Accepted for publication).

17. Piaget J. Piaget's theory. In: Mussen P, ed. Hand book of child psychology; History, theory and methods, vol. 1. New York: John Wiley; 1983. p. 103-28.

18. Gall MD, Borg WR, Gall JP. Educational research: an introduction, sixth ed. White Plains, NY: Longman; 1996.

19. Gagné RM. Domains of learning. Paper presented at the Annual Meeting of the American Educational Research Association, 1971. http://www.eric.ed.gov/PDFS/ED054853.pdf [cited June 2011].

20. Morris SS, Carletto C, Hoddinott J, Christiaensen LJ. Validity of rapid estimates of household wealth and income for health surveys in rural Africa. J Epidemiol Community Health 2000; 54: 381-7.

21. Filmer D, Pritchet LZ Estimating wealth effects without expenditure data-or tears: an application of educational enrolment in states of india. Demography 2001; 38(1): 115-32. In: Moser $\mathrm{C}$ and Felton A. The construction of an asset index measuring asset accumulation in Ecuador, July 2007. Global Economy and Development, CPRC Working Paper, No. 87 , pp. 3

22. Wamani H, Tylleskar T, Astrom AN, Tumwine JK, Peterson S. Mother's education but not fathers' education, household assets or land ownership is the best predictor of child health inequalities in rural Uganda. Int J Equity health 2004; 3: 9.

23. Acham H, Kikafunda JK, Oluka S, Malde MK, Tylleskar T. Height, weight, body mass index and learning achievement in Kumi district, East of Uganda. Scientific Research and Essay 2008; 3(1): 1-8.

24. Kasirye I. Determinants of learning achievement in Uganda. Economic Policy Research Centre, Uganda, 2009. http:// www.csae.ox.ac.uk/conferences/2009-EdiA/papers/325-Kasirye. pdf [cited 10 August 2011]

25. Okumu IM, Nakajjo A, Isoke D. Socioeconomic determinants of primary school dropout: the logistic model analysis. Economic Policy Research Center, Makerere University. MPRA Paper No. 7851. http://mpra.ub.uni-muenchen.de/7851 [cited 10 August 2011].

26. Oluka S, Opolot-Okurut C. Performance in primary education in the Teso region: an exploratory study. Nairobi: UNESCO; 2008. http://www.unesco-uganda.ug/index.php?option=com docman\&task=cat_view\&gid=48 \&Itemid=81 [cited 10 August 2011].

27. Del Rosso JM. School feeding programs: improving effectiveness and increasing the benefit to education. A guide for Program managers. The Partnership for Child Development, 1999.
28. Pollit E. Does breakfast make a difference in school? J Am Diet Assoc 1995; 95(10): 1134-9.

29. Del Rosso JM, Marek T. Class action: improving school performance in the developing world through better health and nutrition. Washington, DC: World Bank; 1996.

30. Uganda Demographic Health Surveys UDHS (2006). Uganda Bureau of Statistics Kampala, Uganda. Calverton, MD: Macro International.

31. Tidemann-Andersen I, Acham H, Maage A, Malde MK. Iron and zinc content of selected foods in the diet of school children in Kumi district, East of Uganda: a cross-sectional study. Nutr J 2011; 10: 81 .

32. Consolidated appeal-Uganda CAP, 2010. Food security and agricultural livelihoods sector monitoring report 05-08/10 Teso. http://www.ugandaclusters.ug/dwnlds/0503CAP08/2010/ MYR-2010/2010_CAP_MR_01-0410_Teso.pdf [cited 3 October 2011].

33. Pollit E, Gersovitz M, Garguilo M. Educational benefits of the US school feeding programme: a critical review of literature. Am J Pub Health 1978; 68(5): 477-481.

34. Buhl A. Meeting nutritional needs through school feeding: snapshot of four African nations. Global Child Nutrition Foundation. University of Washington, School of Public Health. http://www.genf.org/library/Meeting-NutritionalNeeds-Through-School-Feeding.pdf

35. Uganda National Examinations Board (UNEB). The achievements of primary school pupils in Uganda in English and mathematics: National Assessment of Progress in Education 2006. Kampala: Uganda National Examinations Board; 2007.

36. World Bank. (2004). World Development Report: making services work for poor people. Washington, DC: World Bank.

37. King E. The effect of family size on family welfare. In: D.G. Johnson and R.D. Lee, eds. Population growth and economic development: issues and evidence. Madison, Wisconsin: The University of Wisconsin Press; 1987, pp. 373-411.

38. Shareen J. (2004). Female household headship in rural bangladesh: incidence determinants and impact on children's schooling. Economic Growth Center Discussion Paper Series, No. 894, New Haven: Yale University.

39. Hanushek EA, Lavy V. (1994). School quality, achievement bias, and dropout behaviour in Egypt, LSMS Working Paper, No. 107. Washington, DC: World Bank.

40. Sewnet M. Some factors affecting scholastic achievement of elementary school pupils. Thesis, School of Graduate Studies, Addis Ababa University, 1995.

41. Escobal J, Saavedra J, Suárez P. (2005). Changes in school attendance levels and education expenditure in Peru, Young Lives Working Paper, No. 13, London: Young Lives.

\footnotetext{
*Hedwig Acham, PhD

Department of Science, Technical and Vocational Education (DSTVE) Makerere University

P.O. Box 7062, Kampala, Uganda

Tel: +256772330240

Fax: +256414540733

Email: hacham@educ.mak.ac.ug
} 